Letras, Lima. 1977-79. (Nos. 86-87), 145-160.

\title{
El proceso de la significación
}

\author{
DESIDERIO BLANCO
}

\section{Tener sentido}

"Es extremadamente difícil hablar del sentido y decir algo sensato". Con esta afirmación comienza A. J. Greimas su reflexión sobre el sentido. Y la razón consiste en que el sentido constituye una de las evidencias más inmediatas del hombre común y corriente. Las cosas tienen sentido o no tienen sentido de acuerdo con determinados cánones no siempre explícitos; las palabras tienen o no tienen sentido en relación con normas establecidas por diferentes gramáticas y en relación con la situación en que son proferidas; las diversas expresiones del hombre, es decir, la cultura toda, tienen sentido o carecen de él de conformidad con ciertas exigencias que estipula la sociedad en los diferentes niveles de súcorganización ye operación. Tener sentido es, pues, una evidencia r Por lo mismo, es lo más oscuro que pueda imaginarse. Como toda evidencia, el sentido forma parte de la formación ideológica en la que se produce. De ahí la dificultad de decir algo sensato, es decir, con sentido, al hablar del sentido.

¿Qué significa, en definitiva, eso de "tener sentido"? Los diferentes autores que se han preocupado por este problema, ven el sentido como una realidad confusa, amorfa, extendida como una superficie y representada bajo distintas metáforas. Para unos, el sentido es como una tela inconsútil en la que el hablante hace recortes caprichosos, construyendo diversas posibilidades de intelección (Metz); para otros, el sentido es representado por una superficie sin divisiones sobre la que se proyecta la sombra de una red abierta (Hjelmslev ): "la superficie sin dividir es el sentido, la red abierta es la forma y la sombra de la red proyectada sobre la superficie es la sustancia del contenido" (Cfr. Prolegómenos a una teoría del lenguaje, Madrid, Gredos, 1926, cap. 13); para otros, el universo del sentido es como una pantalla de humo en la que una telaraña apenas perceptible representa los millares de diferencias que organizan u ordenan el tejido de 
dicho universo (Greimas). En la "sustancia vaporosa clel mundo" - continúa Greimas - el hombre introduce discontinuidades exploratorias que le permiten entenderlo y manejarlo.

Tener sentido, entonces, no es otra cosa que la posibilidad de entender el mundo, de manejarlo y de controlarlo, orientando los fenómenos que en él se producen a fines determinados por el hombre. Tener o no tener sentido es un fenómeno exclusivamente humano, ya que solamente el hombre puede establecer fines y metas y ordenar las cosas hacia su consecución. La naturaleza no tiene sentido para sí misma, está formada de procesos sin sujeto(s) ni fin(es), y solamente con la aparición del ser inteligente comienzan a descubrirse orientaciones y finalidades. Cada grupo humano, cada cultura, plantea las suyas; de ahí que los fenómenos adquieran diverso sentido según la sociedad en la que se produzcan y el momento histórico en el que tengan lugar. El sentido es un hecho histórico y social por su misma esencia. Hechos y objetos que tienen sentido para unas sociedades, no lo tienen para otras; expresiones que tienen sentido para unos grupos, no lo tienen para otros; códigos que producen sentido en una cultura no lo producen en otras, y así sucesivamente. La historicidad del sentido se descubre ante los restos del pasado: nos resulta difícil descubrir el sentido de determinados objetos utilizados por el hombre primitivo en los diferentes estadios de su desarrollo, cuando nos faltan informaciones sobre su orientación concreta y su finalidad última en la sociedad que los produjo, y ese sentido se convierte en objeto de terca investigación. Así mismo, resulta enigmático el sentido de muchos productos del presente, cuya investigación ocupa la energía y la dedicación de muchos investigadores. titratamos de encontrar el sentido de los procesos sociales en los que estamos inmersos; nos preocupa descubrir el sentido de la vida y de la muerte; queremos alcanzar el sentido del universo en su totalidad; trabajamos constantemente en la identificación del sentido de los innumerables mensajes que se emiten en la sociedad contemporánea y de todos aquellos que han sido emitidos a lo largo de la historia humana. Y cuando encontramos algún sentido en esos fenómenos y en esos mensajes, nos sentimos satisfechos.

\section{Sentido/significado/significación}

Por ser el sentido un fenómeno tan extenso y tan ambiguo, la forma de representarlo y las formas de designarlo son también ambiguas y difusas. Con frecuencia, se habla del sentido bajo los nombres de significado o de significación. Se dice, por ejemplo, que una película tiene un profundo significado o que la significación de un poema no es clara. En ambos casos, se trata de juzgar el sentido de ta- 
les mensajes. Pero no solamente se producen estas interferencias en las expresiones corrientes, sino que los mismos tratados especializados utilizan confusamente los tres términos, sin precisar los alcances de cada uno. La Lingüística moderna y con ella la Semiótica se ha preocupado por diferenciar los conceptos de cada término, a fin de introducir el mayor rigor posible en el análisis de los fenómenos de sentido.

Para Saussure, el significado es el término correlativo del significante en la formación del signo, y su contenido es el concepto o representación mental del objeto o entidad de que se trate. Semánticamente, el significado está compuesto por un conjunto de rasgos sémicos que caracterizan la representación del objeto y que permanecen invariables a lo largo de extensos lapsos en el desarrollo de las lenguas. Tales rasgos son de dos clases: aquellos que reproducen las características perceptibles y aquellos otros que señalan las marcas de la clasificación. Por sus características perceptibles un globo es algo esferoidal, flotante, corporal, hueco, etc.; por sus marcas de clasificación, el globo puede ser terráqueo, aerostático, de juguete, etc. La combinación de estos dos tipos de rasgos es lo que permite que el sentido se manifieste, es decir, lo que permite saber de qué globo hablamos cuando hablamos de un globo. El conjunto de rasgos que definen el significado de un término o significante es configurado históricamente por los hablantes de una determinada lengua.

La significación, en cambio, es una función en el sentido algebraico del término; es decir, la significación resulta de la relación que se establece entre el significante y el significado y consiste en la capacidad que tiene el signo de aludir, de señalar hacia el objeto. Significar es señalar, orientar la atención del receptor por medio de la representacicón contenida en el significado hacia Sla" realidad significada. Esta capacidad referencial del signo, conduce a la situación ideológica del "realismo" lingüístico, en virtud de la cual el significado tiende a ser confundido con el referente. El significado de la palabra "perro" o de la imagen de un perro no es el animal físico, biológico, que denominamos "perro", sino la representación conceptual de lo que es ser perro:/animal/, /mamífero/, /doméstico/, /cánido/, etc. La significación es el proceso por el que el signo alude a la realidad sin alterarla.

Ampliada a las dimensiones de un mensaje completo, la significación constituye el proceso complejo por el que los signos utilizados crean el universo representado.

El sentido es algo más amplio. Está, por un lado, vinculado a la actitud del hablante o emisor. Las mismas relaciones de significación creadas por los signos, producen diverso sentido de acuerdo con la actitud asumida por el emisor ante la situación enunciada. Una expresión como: "Arturo vendrá", puede adquirir tres sentidos dife- 
rentes según sea el tono, la situación y el contexto en que se pronuncie:

1. Una simple información.

2. Una promesa.

3. Una pregunta.

Como ya señalaba Amado Alonso, la actitud del hablante puede ser declarativa, interrogativa, desiderativa, imperativa, y es la que da unidad al pensamiento.

Por otro lado, el sentido configura "un horizonte de significaciones encarnado en la organización de los enunciados" (Cfr. H. Lefebvre: El lenguaje y la sociedad, Buenos Aires, Proteo, 1967), y está formado por un bastidor clasemático (=de rasgos sémicos contextuales, genéricos, clasificatorios), de carácter ideológico, según el cual los significados de los signos se organizan con vistas a la comunicación.

El sentido no se reduce a los límites de la significación; incluye también lo que Lyotard denomina fenómenos de expresión, que no se hallan orientados deliberadamente a la comunicación (Cfr. Discurso, figura, Barcelona, Gustavo Gili, 1979). En esos fenómenos se incluyen las formas de sentido que provienen del deseo, del inconsciente, formas esquivas y fugitivas, fulgurantes e inasibles, formas perturbadoras que se manifiestan en las transgresiones del sistema significante utilizado.

El sentido implica una intencionalidadnunas dirección. La intencionalidad no siempre es consciente, pero siempre actúa, y se presenta como una relación entre el trayecto que se ha de recorrer y la meta que lo cierra.

\section{Estructura elemental de la significación}

La teoría del valor introducida por Saussure en Lingüística, permite descubrir la forma en que se organiza la significación. Cada uno de los rasgos sémicos, o semas, que definen el significado de un signo, está determinado por los semas que lo rodean y de los cuales se diferencia. Cada sistema semiótico establece diversos tipos de relaciones y de diferencias entre las unidades que lo conforman. Así, el español establece una diferencia entre rata y ratón, allí donde el latín no la introducía (="mus" es tanto rata como ratón). La realidad cubierta por el latino "mus" está desglosada en español en dos campos diferentes: el campo de las ratas (animales grandes y repugnantes) y el campo de los ratones o pericotes (animales pequeños y casi simpáti- 
cos). El valor de cada término o unidad significativa es diferente en cada lengua.

Un sema está, pues, definido por su valor diferencial. Se distingue y se entiende un rasgo sémico en cuanto se percibe su relación con otro sema. Esta relación puede ser de semejanza o de contraste. Más aún, semejanza y oposición concurren a la configuración de cada sema. La relación de semejanza permite ver su mutua conexión en el sistema; la relación de oposición lo diferencia del sema más cercano que contribuye a su definición. /Masculinidad/ y /feminidad/ se conectan en el eje de la sexualidad, pero se diferencian por ocupar posi ciones extremas en ese eje. Se denomina eje sémico a esta relación de doble orientación entre las unidades mínimas de la significación. El eje sémico constituye la estructura elemental de la significación. Toda significación surge de una oposición, pues como señala Saussure, "en la lengua, como en todo sistema semiológico, lo que distingue a un signo es todo lo que lo constituye. La diferencia es lo que hace la característica, como hace el valor y la unidad". (Cfr. Curso de lingïística general, Buenos Aires, Losada, 1974, p. 205). La captación de un sema obliga siempre a la inteligencia y comprensión del sema o rasgo sémico que se le opone: entendemos la condición de "blanco" por oposición al rasgo de "negro"; el concepto de "poco" por oposición al de "mucho"; lo "grueso" por diferencia con lo "delgado", y así sucesivamente.

En códigos tan abiertos como el cine, las oposiciones se establecen en formas muy diversas: el plano general se opone al primer plano, pero también al planó americano y al plano medio. La presencia de uno cualquiera de los planos en la cadena de montaje, actualiza por oposición las características de todos los demás que están ausentes, y cuya fuerza actúa, como indica Soussure, in absentia. Existen, no obstante, preferencias opositivas, que son las que primero llegan a la mente de los usuarios (emisor y receptor) y determinan la elección pertinente en la cadena sintagmática (=de montaje). La asociación del cineasta puede actuar por el mayor contraste ( $\mathrm{PG} / \mathrm{PP}$ ) o a través de una progresión gradual de diferencias inmediatas (PG/PC; PC) $\mathrm{PE}$; $\mathrm{PE} / \mathrm{PA}$; $\mathrm{PA} / \mathrm{PM}$; $\mathrm{PM} / \mathrm{PP}$ ), que era el consejo de la escuela.

Por otra parte, el plano del contenido de la imagen tiene que ser verbalizado para ser comprendido. Es decir, en la imagen "leemos" unidades complejas de significado denominadas sememas, o acepciones semánticas. Los sememas son unidades de manifestación del contenido, integradas por rasgos sémicos de carácter permanente y por rasgos sámicos contextuales. Los rasgos permanentes representan las características físicas del objeto; los ragos contextuales permiten clasificarlo en un conjunto determinado. De todos los datos captados por la cámara, solamente algunos resultan pertinentes para reconocer el objeto, y con frecuencia es necesario: recurrir al truco (filtros, com- 
posición, trabajo de laboratorio) para que un objeto aparezca como lo percibe la visión normal. Clara demostración, por lo demás, de que la visión normal es selectiva, culturalmente selectiva, y no "natural". Tales rasgos, sin embargo, no serían reconocibles de no estar insertos en un contexto determinado, razón por la cual ante un objeto que aparece fuera de su espacio habitual, fuera de su contexto, sentimos dificultad para reconocerlo e identificarlo. $\mathrm{Y}$ solamente logramos identificarlo cuando lo nombramos, es decir cuando le aplicamos el semema correspondiente. Semejante dificultad se siente ante objetos que aparecen en filmes etnográficos y que no alcanzamos a nombrar ni a clasificar. Ante las imágenes no-figurativas, la tendencia normal es a descubrir formas y figuras reconocibles que el autor no ha pretendido representar.

\section{Niveles de significación}

Por medio de los signos se puede aludir a la realidad de dos formas diferentes: en forma directa, inmediata, y en forma indirecta, secundaria. La forma directa da origen a la denotación, forma de significación en virtud de la cual el lenguaje designa los objetos de la realidad. La forma indirecta produce la connotación, forma de significación por la que el lenguaje alude a los valores atribuidos a los objetos designados. Un sencillo esquema permite ver la articulación de ambos sistemas en los mismos elementos del lenguaje:

1.

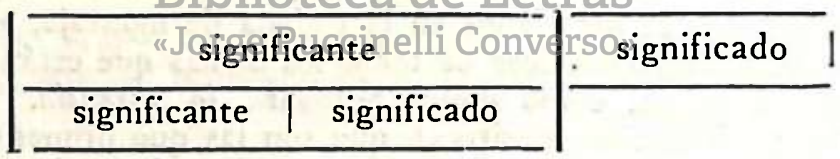

En el nivel 1, el significante y el significado de un signo señalan la existencia real o imaginaria de un objeto, por ejemplo un automóvil. En el nivel 2, con la enunciación del signo automóvil significamos /desplazamiento rápido/, /comodidad/, /velocidad/, /status social/. Pasemos el ejemplo a la imagen cinematográfica: en la primera imagen del filme se nos muestra un automóvil a la puerta de una casa en plano de conjunto corto. En el nivel de denotación, la imagen nos permite reconocer, por medio de la distribución de la luz sobre la superficie de la pantalla, la imagen de un automóvil (en este caso, por las virtudes de la imagen icónica, el automóvil ya no será "el" automóvil, en general, sino "un" automóvil concreto, un Mercedes-Benz, por ejemplo). La imagen del Mercedes-Benz significa lujo, distinción social, riqueza: nivel de connotación. Lo que los sociólogos llaman "signos externos de riqueza" funcionan por connotación. 
La connotación, por ser secundaria, no es menos importante y fundamental. La secundariedad se debe solamente al proceso de producción del efecto de sentido, puesto que necesariamente debe apoyarse en un signo primero para significar. La mayor parte de las significaciones que producimos en nuestra vida, y sobre todo en los mensajes elaborados por el arte, son significaciones de connotación, de tal manera que llega a no ser importante dicha distinción para la producción del sentido.

La connotación quiere decir que el sentido jamás está dado, que el mensaje nunca es simple y que siempre hay más, siempre queda algo que hace eco, efecto de turbación en la transparecencia del sentido funcional, y que recarga de evocaciones la aparente evidencia del mensaje.

\section{Como señala Metz, "siempre hay sentido detrás del sentido".}

Los niveles de connotación se encadenan en forma indefinida. Este fenómeno de significación da cuenta de lo que se llama la "profundidad" de la obra de arte. En la obra de arte, los niveles de connotación se superponen unos sobre otros, hasta llegar a los grados más genéricos de sugerencia. Los niveles de connotación son eminentemente ideológicos, porque se insertan en contextos semánticos cada vez más amplios, contextos que a su vez están formados por conjuntos de rasgos sémicos, cuya función consiste en clasificar los objetos del mundo. Cada cultura elabora sus propias clasificaciones de acuerdo a las necesidades que tiene que resolver. Los niveles de connotación son cada vez más latentes, mientras que la denotación constituye el sentido patente del chensaje.cinelli Converso"

\section{La ilusión referencial}

Ya hemos indicado que existe la tendencia natural, es decir, ideológica, a identificar el significado de un signo con su referente. Por este mecanismo ideológico se llega a la reificación del significado, fenómeno que produce la denominada "ilusión referencial". Para dilucidar este problema, Peirce estableció una distinción entre referente interno (Immediate Object) y referente externo (Dynamic Object). El referente interno es "la forma en que el objeto es representado por el signo" (Cfr. Collected Papers, 4536).

A partir de esta doctrina semiótica, Umberto Eco ha elaborado su teoría del significado como unidad cultural. Los estímulos que recibimos del mundo son organizados en unidades de reconocimiento que nos permiten representar los diversos objetos de la realidad. Esas unidades son elaboradas siguiendo determinadas normas sociales establecidas en el contacto diario con los objetos. La necesidad de dis- 
tinguir una cebra de una hiena, por ejemplo, determina que la unidad cultural de representación del objeto "cebra" sea diferente en una cultura selvática y en otra cultura de puna, en la que el objeto "cebra" deba ser distinguido del objeto "yegua", por ejemplo. Los rasgos sémicos de ambas unidades culturales serán diferentes. Mientras que el rasgo/rayas sobre la piel// puede ser pertinente para distinguir "cebra" de "yegua", no lo es para distinguir "cebra" de "hiena", en cuyo caso la representación acudirá a rasgos tales como /hocico largo/-/hocico corto/ u otros por el estilo. El significado semiótico de un signo no es otra cosa que la codificación socializada de una experiencia perceptiva.

Esto no quiere decir que los signos no remitan a la realidad. Ciertamente que lo hacen, pero a través de mediaciones culturales de orden social e histórico, que es necesario tomar en cuanta al establecer el valor de los signos de un código. Por otra parte, los signos no son entidades subjetivas, sin ninguna relación con la realidad, lo que nos encerraría en un idealismo insalvable. Las unidades culturales que constituyen el significado o referente interno de los signos, están determinadas materialmente por los estímulos exteriores de los objetos. Sin embargo, no es posible concebir este reflejo en forma mecánica y simplista. El reflejo se produce sobre un espejo condicionado por una cultura y por una historia. Por otra parte, la ubicación del espejo resulta también determinante para captar el reflejo; es decir, el reflejo está determinado materialmente no sólo por la cultura, sino también por la posición que el sujeto ocupa en la sociedad, especialmente por la posición de clase en una sociedad de clases. En este sentido, se puede afirmar que las unidades culturales están físicamente a nuestro alcance. Son los signos que la vida social pone a nuestra disposición. (Cfr. Eco, Tratado de semiótica general, Barcelona, Lumen, 1977). Con la introducción del concepto de "unidad cultural" se evita la metafísica del referente a la que tan propensa es la ilusión refetencial.

La ilusión referencial se produce con mayor facilidad en los códigos icónicos, pues el objeto representado ostenta los mismos caracteres del objeto real. La fotografía y el cine han acentuado esta ilusión al producir sus signos con procedimientos mecánicos que registran los reflejos físicos, luminosos, de los objetos fotografiados. Sin embargo, es claro que el contenido de una imagen no es el objeto real, tal como existe en el mundo extra-semiótico, sino un objeto representado, construido por medio de selecciones y combinaciones conscientes o inconscientes. La ideología propia del cine consiste, precisamente, en esa ilusión de reaildad que producen sus imágenes. El naturalismo burgués ha encontrado su plenitud de representación en la imagen cinematográfica, que nos permite ver el mundo en movimiento, tal como se desarrolla ante nuestros ojos cotidianos, aunque para ello tenga que 
modificar la materialidad del reflejo directo a fin de conseguir las condiciones culturales de la percepción. El uso de filtros, por ejemplo, tiene esa finalidad, así como otros trucos corrientes en el medio cinematográfico.

La ideología dominante promueve la "ilusión referencial" por medio de la representación y de la narración en los diversos medios de expresión. Frente a ella, las vanguardias, el cine independiente, "underground", el video-arte, trabajan contra la ilusión referencial, destruyendo las formas narrativas o representativas o ambas a la vez, o incluso utilizándolas contra sí mismas. En esta operación, la ilusión de realidad cede terreno ante el trabajo de la escritura, que promueve la presencia del significante en la producción del sentido.

\section{La producción del sentido}

Porque el sentido no está dado de antemano, sino que se produce. El sentido es el resultado de un trabajo con los signos. Las operaciones de producción del sentido se enmarcan en los dos ejes fundamentales que organizan todo código: el eje paradigmático y el eje sintagmático. El eje paradigmático agrupa todas las oposiciones del sistema, oposiciones que surgen de las diferencias entre las distintas unidades que lo conforman. De estas unidades diferenciales, el emisor debe escoger, en cada caso, la que mejor se ajusta a sus necesidades comunicativas y expresivas. Esta es una operación de selección y determina qué unidades, qué elementos pasarán a formar parte del mensaje concreto que se está produciendo, así como el sentido final que dicho mensaje producirá. Pero quedan las otras, las unidades no seleccionadas, las unidades "olvidadas", que pudiendo estar en el mensaje no lo están, y cuya ausencia también es significativa. Es significativa porque, como ya habíamos indicado anteriormente, contribuyen a definir el valor de las unidades que han sido elegidas para formar el mensaje; pero además son significativas, porque su "olvido", tiene razones que la razón no comprende. Y es aquí donde entran a tallar en la interpretación, métodos como el psicoanálisis o la psicocrítica.

El eje sintagmático es el eje de las combinaciones, mejor dicho, el eje de las reglas de combinación entre las unidades. Las unidades seleccionadas deberán ser colocadas en un orden determinado, orden temporal o espacial, o ambos, según los códigos. La materia significante que utiliza el código, señalará las condiciones de dicho orden. Así, por ejemplo, el código de la lengua impone un orden temporal, de carácter lineal, sucesivo, como todo lo qué se desarrolla en el tiempo. La escritura ampliará este orden a un orden espacial, cambiante de escritura a escritura. Nuestra escritura impone el orden de izquierda a derecha y de arriba abajo; las escrituras orientales, o al menos 
algunas de ellas, imponen un orden de derecha a izquierda y de arriba abajo; otras aún, un orden vertical de arriba abajo y de derecha a izquierda. Los resultados son diferentes, pues determinan formas de pensar y de representar concomitantes, que es necesario tomar en cuenta a la hora del análisis. Los medios de comunicación masiva, por ejemplo, están alterando nuestras formas de representación escritural, lineal, de implicación lógica ("post hoc, ergo propter hoc"), con la estructura de mosaico que imponen a sus mensajes. El código de la pintura impone un orden espacial, del que surgirá un tiempo de lectura. La disposición de las unidades en el espacio está regida por leyes que establece el código de la pintura. El cine, por su parte, impone un orden mixto y complejo: por un lado, establece la disposición de las unidades icónicas en la superficie de la pantalla, como la pintura; por otro lado, señala una sucesión temporal entre las unidades así compuestas (=encuadres), organizadas por las leyes del montaje (leyes sintagmáticas), y establece aún relaciones entre unidades de orden visual y sonoro, relaciones simultáneas a las que rigen la cadena de cada orden por separado.

La sintagmática no ofrece el mismo rigor en todos los códigos. Hay códigos rígidos y códigos laxos. Los primeros, como la lengua, exigen que todas las combinaciones se ajusten a reglas estrictas: de posición, de orden, de concordancia, etc. Los segundos dejan mucha libertad para efectuar la combinación entre las unidades, llegando incluso a la supresión total de reglas de combinación. En este caso, la combinación elegida es responsabilidad absoluta del emisor, y su elección marca mejor sus preferencias y sus determinaciones.

No puede, sin embargo, existir un código sin paradigma, pues en tal caso sus unidades no se diferenciarían entre si, ni de otros elementos adyacentes. Con frecuencia, no obstante, los códigos acuden a diferencias con elementos inexistentes, con la nada significante. Se habla entonces de términos no marcados o de significante cero. Algunos ejemplos ilustrativos: En el cine, el sonido se opone paradigmáticamente al silencio, que no es otra cosa que la ausencia de sonido. En el cine mudo, el silencio no significaba nada, era una simple carencia; en el cine sonoro, el sonido significa por su oposición diferencial con el silencio. Cuando se pone en marcha un automóvil, comienza a funcionar un sistema de señales direccionales. Si el automóvil que va delante de nosotros, hace oscilar su luz direccional a la derecha, entendemos que el automóvil va a doblar a la derecha, y aminoramos la marcha. Si no hace ninguna señal con su luz direccional, entendemos que el automóvil sigue adelante, a su misma velocidad. Si de hecho dobla a la derecha, es posible que nos choquemos con él, con la discusión correspondiente, propia del caso. La ausencia de señal es señal de seguir adelante. La economía del código es el principio que actúa en la base de estos mecanismos de significante cero. 
La selección y la combinación de las unidades van configurando la estructura del mensaje y produciendo sus efectos de sentido. Selección y combinación están regidas, en última instancia, por la actitud del emisor, por sus determinaciones sociales y personales, determinaciones que se conocen como condiciones de producción. Los receptores solamente contamos con la estructura del mensaje para decodificar su sentido y para reconstruir, a partir de su estructura, las condiciones de producción. A esta labor pueden concurrir, indudablemente, ciencias como la sociología, el materialismo histórico, el psicoanálisis y otras, según su pertinencia.

\section{Estructura del mensaje}

Bernard Pottier, plantea que todo mensaje resulta de la formulación de relaciones entre designaciones. En fórmula simple:

\section{$M=F\left[D_{1}<R>D_{2}\right]$}

Las designaciones están referidas a las entidades y a los comportamientos. Cada código dispone de distintos medios para designar objetos y comportamientos: la lengua natural utiliza los morfemas lexicales o lexemas, llamados vulgarmente palabras; el cine designa por medio de la mostración icónica, tanto entidades como comportamiento.

El cine es un medio deíctico por excelencia; su capacidad mostrativa es la base de cüalquier otra función que pueda cumplir, como la narración, por ejemplo. Las designaciones cinematográficas son infinitas, y su organizacion resufta por demás difícil. La lengua natural, con sus operaciones metalingüísticas, nos ayuda en esa tarea, pues la imagen para ser identificada necesita ser nombrada (Cfr. Ch. Metz: "Lo percibido y lo nombrado" en Essais sémiotiques, Paris, Klincksieck, 1977). Los elementos mostrados en la imagen pueden ser organiazdos siguiendo los siguientes criterios:

- Oposición, de carácter paradigmático, entre elementos del mismo nivel, del mismo campo semántico. En este sentido, distinguimos un caballo de un burro; una gallina de un conejo; un automóvil de un camión, etc.

- Inclusión, entre los elementos del paradigma y el campo que los abarca: la gallina está incluida entre los animales domésticos; la anchoveta, entre los pescados; la casa, entre los construcciones, etc.

- Participación, entre elementos de distinto campo semántico relacionados en la experiencia social: librero, chofer, constructor, pescador, etc. 
- Asociación, entre elementos cuya relación en la experiencia social es virtual. El pavo evoca la Navidad; el rojo se asocia con el peligro; las golondrinas, con la primavera; las llaman, con el amor; los buitres, con la muerte, etc.

Las relaciones que pueden establecerse entre las designaciones son: la voz, la actancia y la integración.

En el cine, tanto la atribución como la acción, se muestran de la misma manera. Es la lengua la que nos permite distinguir entre "perseguir" y "ser perseguido", "amar" y "ser amado", "golpear" y "ser golpeado". En el cine, ambas relaciones se expresan como comportamientos. Por otra parte, el cine no dispone de mecanismos para expresar los procesos interiores. No puede decir, por ejemplo, que Napoleón sentía miedo, o que pensaba tal o cual cosa, sin acudir a los recursos de la lengua. Para expresar tales fenómenos debe haccrlo indirectamente, por medio de indicios, por la captación y mostración de los comportamientos exteriores. En este sentido, el cine es eminentemente conductista.

La actancia es el conjunto de relaciones que se establecen entre los actantes o participantes del enunciado y del relato. Los actantes se estructuran en un modelo:

\section{DESTINADOR $\rightarrow$ OBJETO $\rightarrow$ DESTINATARIO \\ AYUDANTE $\rightarrow$ SUJETO $\leftarrow$ OPONENTE \\ "Jorge Puccinelli Converso"}

La relación fundamental entre los actantes del relato es la yunción, relación que adopta las formas siguientes:

\section{/conjunción/ _ / / _isyunción/}

y. que articula al sujeto con el objeto. Todo relato, incluido el relato cinematográfico, consiste en una sucesión de estados de conjunción y de disyunción, así como de las transformaciones que se producen entre ellos.

La integración es un fenómeno propiamente lingüístico, que no tiene ninguna aplicación en códigos como el cine. Se refiere a los fenómenos de adjetivación, síntesis y aspecto verbal.

Las formulaciones son aquellas operaciones semióticas que expresan la actitud del hablante o emisor ante la realidad significada. En esta categoría se incluyen la aserción, la determinación, la calificación 
y cuantificación, la modalidad y la situación de locución. Las lenguas han desarrollado enormemente la clase de las formulaciones, ya que de la actitud del emisor depende la producción del sentido.

También el cine ha desarrollado una serie de recursos para expresar la actitud del emisor frente a la realidad representada: la planificación, los ángulos de toma, los movimientos de cámara, la composición del cuadro, los trucos, la iluminación y la selección de los colores forman parte de la clase de las formulaciones. Pero es, sobre todo, el montaje el que mejor expresa esta dimensión de la estructura del mensaje: el montaje alternado, el montaje paralelo, el montaje lineal, el tonal, el métrico, el serial, el durativo, etc., son otras tantas formas de formulación semántica.

La aplicación de estos procedimientos, consciente o inconscientemente, da por resultado el mensaje que el receptor recibe y cuyo sentido dilucida. Para captar el sentido, es preciso hacer el recorrido inverso: pasar de la identificación de las operaciones de producción a la actitud del emisor y de la actitud del emisor a las condiciones que la determinan. El conocimiento del código constituye una condición imprescindible para lograrlo. Sin código no hay comunicación posible.

\section{El sentido como energía}

El sentido es una forma de energía psíquica organizada. Los recorridos que efectúa esta energía se ubican, según la primera tópica freudiana, en los tres niveles del aparato psíquico: inconsciente preconsciente - consciente, pero en cada uno con particularidades muy diferentes. En"ePlsistema consciente, ell sentido se presenta como energía ligada, y las ligaduras que la oprimen son las exigencias de los sitemas semióticos en su variada diversidad. Reglas gramaticales, sistemas de oposición, ejes paradigmáticos y ejes sintagmáticos de los más diversos tipos canalizan la energía psíquica para ponerla al servicio del pensamiento consciente. En estos sistemas el preconsciente trabaja tanto como el consciente o tal vez más, ya que los sistemas de oposición y las reglas gramaticales y semióticas operan en el tránsito del preconsciente al consciente. Eso quiere decir precisamente la expresión de Saussure "in absentia", referida a la acción de los elementos ausentes del paradigma en la determinación del sentido del mensaje. Es éste el trabajo de la elaboración secundaria.

Pero existe otra forma de energía, la energía no ligada, que recorre libremente el aparato psíquico y que pugna constantemente por surgir a la superficie textual del mensaje como un surtidor incontenible. Es la energía gobernada por el deseo bajo el impulso del principio del placer, que se burla, siempre que puede, de las normas gramaticales que controlan los procesos secundarios. El sentido que surge 
de este régimen de energía no es un sentido racional, no es un sentido "significado", sino un sentido "expresado", sugerido, latente, cuya formulación no es otra que la de sus operaciones de producción. Los mecanismos que lo producen son los mismos que rigen los procesos primarios: condensación, desplazamiento, figuralización y deformación. Los resultados visibles de tales operaciones son las transgresiones de todo tipo que sufren los sistemas secundarios de significación. La retórica ha hecho el inventario de los diferentes recursos de transgresión que en cada época han sido elaborados para lograr la expresión del otro sentido primario.

Entre ambos tipos de energía, entre ambos regímenes del deseo, existen grados intermedios de secundarización, cuyos efectos se observan en los diversos mensajes que se producen en la cultura de nuestro tiempo. Es lo que se conoce actualmente como fenómenos de deconstrucción. La deconstrucción puede afectar a distintos niveles y códigos del mensaje: en unos casos, es el código del relato el que sufre violentas alteraciones, como sucede en Ocho y medio (F. Fellini), El año pasado en Marienbad (A. Resnais), el último cine de Godard: Número dos, Aqui y allá, Sálvese quien pueda; Rayuela (J. Cortázar), La casa verde (M. Vargas Llosa), etc.; en otros casos, la deconstrucción afecta a los códigos de la representación: tal es el caso en obras de la vanguardia más radical como Malone muere (S. Beckett), Finnegans Wake (J. Joyce), Sinfonia diagonal (V. Eggeling), Ritmo 21 y Ritmo 23 (H. Richter), Vitesses Women (C. Eizykman), La región central (M. Snow), Ultra-rojo Ultra-violeta (G. Fihman), las películas de N. MacLaren y los actuales experimentos del Video-Arte, entre los que sobresalen los Happenings de Wolf Vostell y los trabajos de Nam June Paik.

Los resultados de la deconstrucción consisten en opacar la transparencia del signo y en impedir el acceso directo al significado; consisten en poner en primer término el trabajo productivo del significante y en liberar la energía del sentido, atada por las ligaduras de la racionalidad. Ese otro sentido liberado produce malestar, inseguridad, angustia. Por eso resulta profundamente crítico y perturbador, a tal punto que el sistema lo rechaza y lo margina. Pero produce también, como ha señalado $R$. Barthes, por un instante, con la celeridad del rayo, el más intenso placer, el goce más penetrante, en el que el sujeto se pierde como en un orgasmo.

Sin embargo, la emergencia de la actividad significante en el seno del mensaje no es suficiente para especificar ni su modernidad ni su criticidad, pues "existen muchas obras que se saben adornar con una factura de buena calidad deconstructiva, salpicando el discurso con puntuales surgimientos de la enunciación, pero reducidos a simples variaciones ornamentales perfectamente encauzadas por la estructura narrativa general. La ilusión referencial, que parece vacilar por 
un momento, retoma muy rápidamente sus derechos y sale reforzada de la prueba" (A. Gardies, "El espacio del relato fílmico" en: VidieoFonum 7, Caracas, 1980). Quedando a salvo lo esencial, la emergancia de la actividad significante, aporta la plusvalía de un simple signo de modernidad. Si no cuestiona la relación que el receptor mantiene con su objeto, si no provoca una verdadera mutación en el acto de consumo, sino obliga al receptor a redefinir su propio lugar en el proceso de significación, se condena a ser recuperada, muy rápidamente, por las formas dominantes del relato.

\section{REFERENCIAS BIBLIOGRAFICAS}

1. GREIMAS, A. J., En torno al sentido, Madrid, Edit. Fragua, 1974.

2. HJELMESLEV, L., Prolegómenos a una teoría del lenguaje, Madrid, Edit. Gredos, 1962.

3. METZ, Ch., El significante imaginario. Psicoanálisis y Cine, Barcelona, Gustavo Gili edit., 1979.

4. POTTIER, B., Gramática del español, Madrid, Ediciones Alcalá, 1971.

5. LEFEBVRE, H., El lenguaje y la sociedad, Buenos Aires, Edit. Proteo, 1967.

6. LYOTARD, J. F., Discurso, figuro, Barcelona, Gustavo Gili edit., 1979.

7. DE SAUSSURE, F., Curso de lingüistica general, Buenos Aires, Edit. Losada, 1974.

8. PEIRCE, Ch. S., La ciencia de la semiótica, Buenos Aires, Edit. Nueva Visión, 1974.

9. ECO, U., Tratado de semiófice general, México, Nueva Imagen + Lumen, 1978.

10. FREUD, S., La interpretación de los sueños, Madrid, Alianza Editorial, 1972.

11. GARDIES, A., "El espacio del relato filmico" en: Video-Forum 7, Caracas, 1980.

12. EIZYKMAN, C., La jouissance-cinéma, Paris, Union Générale d'Éditions, 1976. 